\title{
First record of Schoenoplectiella xuzenensis (Ohwi ex T. Koyama) Hayasaka (Cyperaceae) from Korea
}

\author{
Jonghwan Kim, Minha Kim ${ }^{1}$ and Muyeol Kim* \\ Department of Biological Sciences, Chonbuk National University, Jeonju 54896, Korea \\ ${ }^{1}$ National Institute of Biological Resources, Seo-gu, Incheon 22689, Korea \\ (Received 8 May 2016; Revised 3 June 2016; Accepted 5 June 2016)
}

\section{사초과 올챙이골속의 한국 미기록종: 고창고랭이 \\ (Schoenoplectiella ×uzenensis (Ohwi ex T. Koyama) Hayasaka)}

\author{
김종환 · 김민하 ${ }^{1}$ - 김무열* \\ 전북대학교 자연과학대학 생명과학과 \\ 1국립생물자원관 유용자원활용과
}

\begin{abstract}
A newly recorded species, Schoenoplectiella xuzenensis (Ohwi ex T. Koyama) Hayasaka, was found in Chosan Lake, Gosu-myeon, Gochang-gun, Jeollabuk-do, Korea. Schoenoplectiella ×uzenensis differs from its related species in having short rhizomes and 1 to 3 spikelets showing inflorescence. Schoenoplectiella triangulata has very short rhizomes and 520 spikelets with inflorescence. Schoenoplectiella lineolata has long creeping rhizomes and 1 spikelet showing inflorescence. We propose the new Korean name of 'Go-Chang-GoRang-Ei' based on its initial collection site. A description, line drawing, color photographs, table, and a species key of Korean Schoenoplectiella are provided for species identification.
\end{abstract}

Keywords: Schoenoplectiella ×uzenensis, Schoenoplectiella, Cyperaceae, new record

적 요: 한국 미기록종인 고창고랭이(Schoenoplectiella ×uzenensis (Ohwi ex T. Koyama) Hayasaka)를 전라북 도 고창군 고수면의 저수지에서 발견하였다. 고창고랭이는 짧게 기는 지하경이 있고 소수가 1-3개가 달리는 데 반하여, 송이고랭이(S. triangulata)는 지하경이 아주 짧고 줄기가 빽빽이 모여나며 소수가 5-20개가 달리 고, 제주올챙이골(S. lineolata)은 지하경이 길게 발달하고 소수가 1개가 달려 뚜렷이 구별된다. 이 미기록종 의 국명은 고창군에 자라기 때문에 '고창고랭이'로 하였고, 고창고랭이에 대한 기재, 도해, 칼라도판 및 근연 종 사이의 차이점을 검색표와 표로 제시하였다.

주요어: 고창고랭이, 올챙이골속, 사초과, 미기록

사초과(Cyperaceae Juss.)의 올챙이골속(Schoenoplectiella Lye)은 세계적으로 60 여 분류군이 분포한다(Govaerts, 2012).

올챙이골속은 오랫동안 고랭이속(Scirpus L.)에 포함되 어 왔으나, Lye (2003)와 Jung and Choi (2010) 등에 의해 고
랭이속이 다계통으로 인식되어 독립된 속으로 취급하고 있다. 올챙이골속은 Lye (2003)에 의해 ‘줄기기부의 인편안 에 암꽃이 달리는 형태'로 독립된 속으로 분리되었으나, 속의 특징을 '소수는 대가 없이 줄기에 밀착하여 달리고 포는 줄기와 유사한 형태적 특징'으로 재설정한 Jung and

\footnotetext{
*Author for correspondence: mykim@jbnu.ac.kr
} 
Choi(2010)의 견해를 전적으로 지지한다. 우리나라 올챙 이골속 식물은 다년초로 주로 강변, 저수지 가장자리, 산 지 습지 등 축축한 물가에 분포한다. 근경은 발달하거나 발달하지 않으며, 화서는 대가 없이 줄기에 밀착하여 가 측생(pseudolateral)하고, 포엽은 줄기와 비슷한 형태로 줄 기에서 연장되며, 소수 인편은 흔히 돌려 달리며 끝이 뾰 족하거나 까락모양이 된다. 주두는 2-3개로 갈라지고, 수 과의 단면은 양면이 볼록한 렌즈형이거나 삼릉형이고 표 면에 가로 주름이 있거나 밋밋하다(Jung and Choi. 2010, 2011; Hayasaka. 2012).
한국에선 오랫동안 올챙이골속 식물을 고랭이속에 포함 하여 6-7분류군이 분포하는 것으로 인식되어 왔고(Lee, 1996; Lee. 1999; Im, 2000; Lee, 2006; Oh, 2007). 한국산 올챙이 골속은 Jung and Choi (2010)에 의해 고랭이속에서 올챙이골 속으로 신조합한 5 분류군을 포함하여 총 7 분류군을 취급하 였고, 이후 미기록종인 나도송이고랭이(S. × xtrapezoidea (Koidz.) J. Jung \& H. K. Choi)를 포함하여 총 8분류군을 취급 하였으며(Jung and Choi, 2011), Cho et al.(2016)에 의해 나래송 이고랭이(S. mucronata var. tatarana (Honda) Yashiro)가 추가로 보고되어 한국에는 9분류군이 분포하는 것으로 알려졌다.

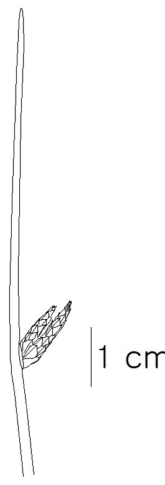

B-1

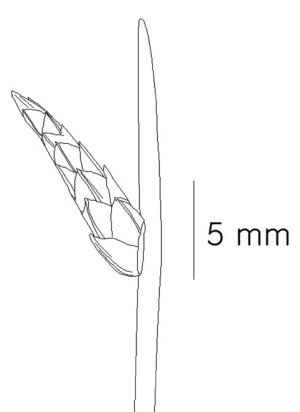

B-2

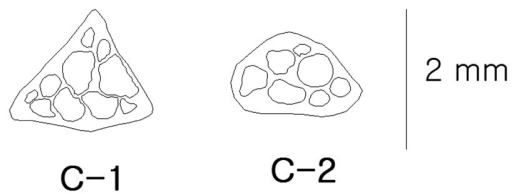

C-1

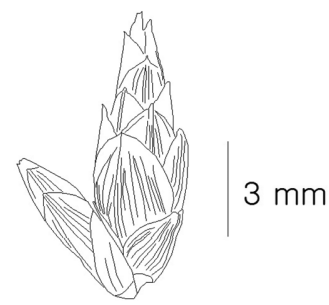

E

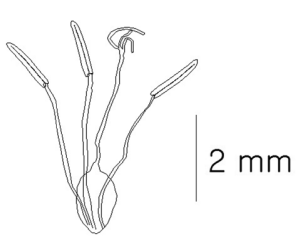

F

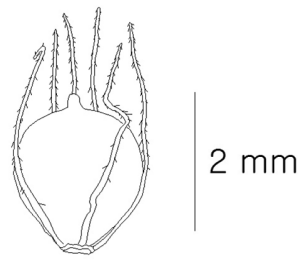

G

Fig. 1. Schoenoplectiella $\times$ uzenensis (Ohwi ex T. Koyama) Hayasaka. A. Habit; B. Inflorescence; C. Culm cross section; D. scale; E. Spikelet; F. Flower; G. Achene 
한편, 고창고랭이(Schoenoplectiella ×uzenensis (Ohwi ex T. Koyama) Hayasaka)는 송이고랭이(S. triangulata (Roxb.) J. Jung \& H. K. Choi)와 제주올챙이골(S. lineolata (Franch. \& Sav.) J. Jung \& H. K. Choi)의 잡종으로 Koyama (1958)에 의해 고랭이 속(Scirpus)인 S. ×uzenensis Ohwi ex T. Koyama로 기재되었고, 이후 Hayasaka and Ohashi (2000)에 의해 Schoenoplectus 속으 로 이속되어 S. xuzenensis (Ohwi ex T. Koyama) Hayasaka \&
H. Ohashi로 신조합되어 다루어져 왔고, 다시 Hayasaka (2012)에 의해 올챙이골속(Schoenoplectiella)으로 이속되며 S. xuzenensis (Ohwi ex T. Koyama) Hayasaka로 신조합 되었다. 본 연구는 고창고랭이가 전라북도 고창군 저수지 가장 자리에 자생하고 있는 것이 확인되어, 이 미기록종에 대 해 형태학적으로 기재하고 근연종과의 차이점을 검색표 와 표로 제시하였다.

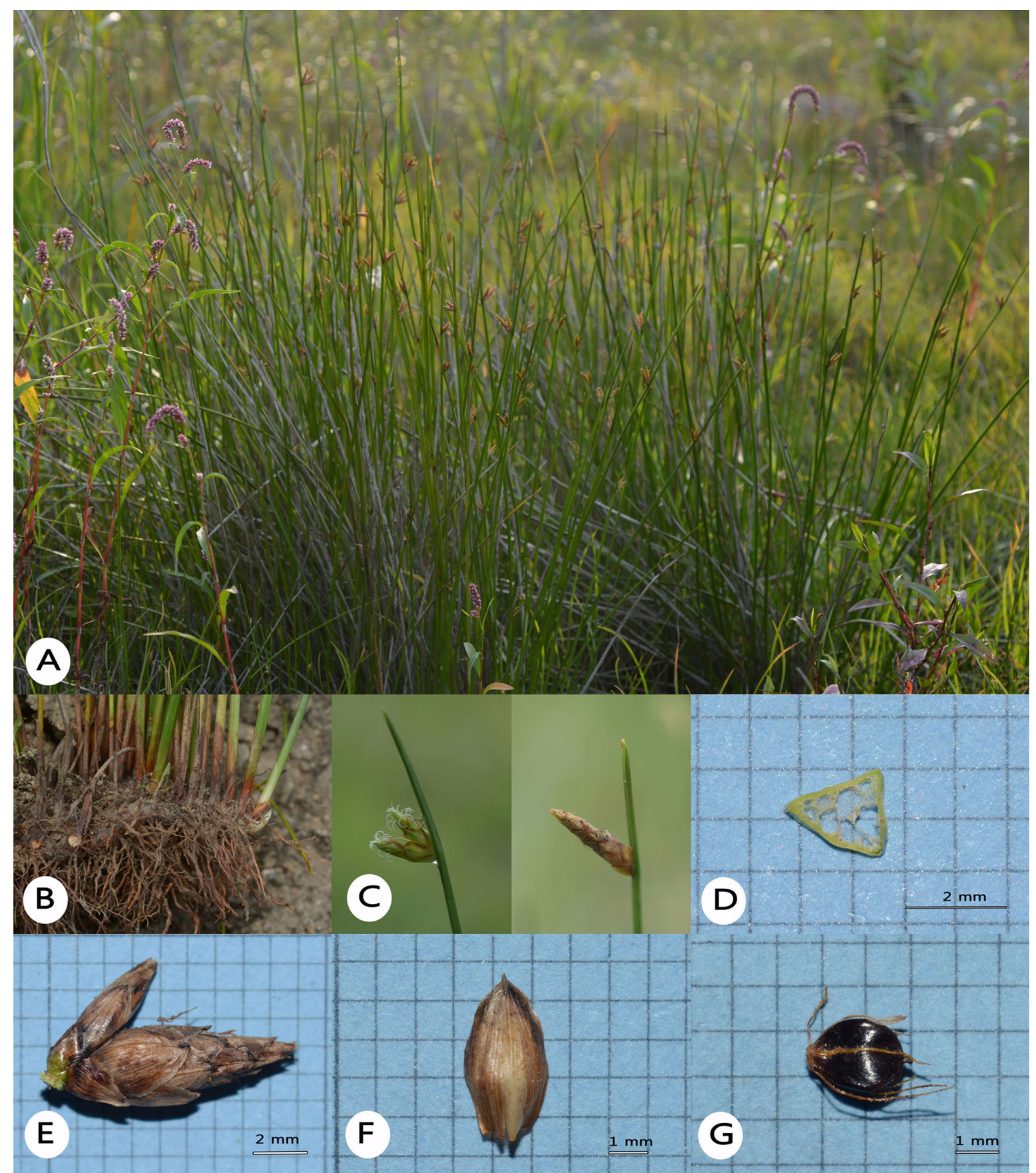

Fig. 2. Photographs of Schoenoplectiella xuzenensis (Ohwi ex T. Koyama) Hayasaka taken in Josan-Lake, Gosu-myeon, Gochang-gun, Jeollabuk-do on Sep. 18, 2014. A. Habit; B. Rhizome; C. Inflorescence; D. Culm cross section; E. Spikelet; F. Scale; G. Achene. 
Table 1. Comparison of morphological characters between Schoenoplectiella $\times$ uzenensis and its related taxa.

\begin{tabular}{lccccc}
\hline \hline \multicolumn{1}{c}{ Character } & S. ×uzenensis & S. triangulata & S. lineolata & S. hotarui & S. juncoides \\
\hline Plant length $(\mathrm{cm})$ & $22-46$ & $50-120$ & $5-30$ & $30-80$ & $20-60$ \\
Rhizome & short & verry short & long creeping & verry short & verry short \\
Culm cross section & round to 3-angled & 3 -angled & round & round & obtuse 5-6 angles \\
Culm thickness (mm) & $0.8-1.7$ & $5-10$ & $0.8-1.2$ & $1-2$ & $1.5-3$ \\
Spikelets & $1-3$ & $5-20$ & 1 & $2-5$ & $3-9$ \\
Spikelet length (mm) & $7.1-32$ & $10-20$ & $4-6$ & $6-14$ & $8-17$ \\
Spikelet width (mm) & $2.2-3.4$ & $4-6$ & $2-3$ & $4-6$ & $3-7$ \\
Scale length (mm) & $3.8-4.6$ & $4-5$ & $4-4.5$ & $4-5$ & $3-4$ \\
Scale apex & mucronate & mucronate & obtuse & mucronate & mucronate \\
Perianth bristles & 6 & $5-6$ & $4-6$ (sometimes 0$)$ & 6 & 6 \\
Achene length $(\mathrm{mm})$ & $2.1-2.7$ & $2.0-2.5$ & $1.7-2.2$ & $2.0-2.5$ & $2.0-2.5$ \\
\hline
\end{tabular}

\section{분류군의 기재}

\section{Schoenoplectiella xuzenensis (Ohwi ex T. Koyama)}

Hayasaka, J. Jap. Bot. 87(3): 184 (2012). Figs 1-2. Scirpus хuzenensis Ohwi ex T. Koyama, J. Fac. Sci. Univ. Tokyo, sect. 3,7: 363 (1958). Schoenoplectus ×uzenensis (Ohwi ex T. Koyama) Hayasaka \& H. Ohashi, J. Jap. Bot. 75: 224 (2000).

\section{국명: 고창고랭이 Go-Chang-Go-Rang-Ei}

다년초로 근경은 짧게 뻗으며 많은 줄기를 낸다. 줄기 는 길이 22-46 cm, 직경 $0.8-1.7 \mathrm{~mm}$ 로 단면은 둥글거나 둔한 삼릉형이다. 잎은 줄기아래에 엽신이 없는 초상엽 으로 1-2개가 있다. 화서는 줄기 상부에 가측생하며 1-3 개씩 달리고 소수는 길이 7.1-32.0 mm, 나비 2.2-3.4 mm 로 난형-장타원형이고 때로 길게 선상원주형으로 되기 도 한다. 포엽은 줄기에서 연장된 형태로 길이 $1.9-4.2 \mathrm{~cm}$ 로 줄기와 모양이 같다. 인편은 황갈색으로 난형-장난형 이고 길이 3.8-4.6 mm, 너비 2.1-2.5 mm로 위쪽 가장자리 가 거칠어 매끈하지 않고 중앙맥이 까락처럼 짧게 돌출 한다. 수술은 3 개이며 약의 길이는 $1.3-1.6 \mathrm{~mm}$ 이고, 암술 머리는 3 개로 갈라진다. 화피편은 6 개로 수과보다 1-1.5 배정도 길며 아래쪽을 향하는 잔 가시가 있다. 수과는 도 란형으로 길이 2.1-2.7 mm, 너비 1.6-1.8 mm로 한면이 볼 록한 삼릉형이고, 약간의 광택이 있으며 밋밋하고 짙은 흑갈색으로 성숙한다.

개화 결실기: 6-10월.

서식 환경: 저수지 가장자리의 축축한 곳.

국내분포: 한국(전라북도 고창군).

국외분포: Japan.

관찰표본: Jeollabuk-do, Gochang-gun, Gosu-myeon, Chosan
Lake. 23 Jun. 2014, J.H KIM 141170-141173 (JUN). 18 Sep. 2015, J.H KIM 152533-152536 (JUN).

고창고랭이(Schoenoplectiella ×uzenensis (Ohwi ex T. Koyama) Hayasaka)는 식물체 크기가 제주올챙이골 $(S$. lineolata)과 송이고랭이(S. triangulata)의 중간크기로 줄기 단면은 2종의 특징에 따라 원형과 삼각형이 한 개체에서도 나타나며, 소수는 제주올챙이골과 유사하나, 인편의 형태 는 송이고랭이와 유사하고, 화서는 1-3개의 소수로 이루어 져 있으며, 외부 형태가 송이고랭이와 제주올챙이골의 중 간 형태로 식물체 크기가 올챙이골(S. juncoides (Roxb.) Rye), 좀올챙이골 $(S$. hotarui (Ohwi) J. Jung \& H. K. Choi)과 유사하 나 올챙이골과 좀올챙이골은 줄기가 원형이거나 약간 각 이진 원형이고, 소수 형태가 난형이므로 한국에 자생하는 올챙이골속에 속하는 9분류군(Jung and Choi, 2012; Cho et al., 2016)의 식물들과 쉽게 구별된다(Table 1).

이와 같이 고창고랭이는 제주올챙이골과 송이고랭이 가 혼생하는 지역에 30 여 개체가 흩어져 서식하고 결실 이 비교적 잘되고 있으나 제주올챙이골과 송이고랭이 2 분류군의 특징이 섞여 있어 제주올챙이골과 송이고랭이 의 자연잡종이 맞는 것으로 판단된다. 이 미기록종은 고 창군에서 서식을 처음 확인하였으므로 국명을 '고창고랭 이’라고 명명하였다. 고창고랭이는 전라북도 고창군 고 수면 저수지 가장자리에 자라며, 주변에는 송이고랭이, 제주올챙이골, 물그령, 물하늘지기, 푸른하늘지기, 민하 늘지기, 솔방울골 등이 함께 발견된다.

\section{고창고랭이와 근연 분류군에 대한 검색표}

1. 지하경은 길게 신장하며, 화서는 1 개의 소수가 달린다 .... 제주올챙이골 S. lineolata

1. 지하경은 없거나 짧으며, 화서는 1개 이상의 소수가 
달린다.

2. 식물체는 대형이고 줄기 단면은 삼각형 한가지만 있다.

3. 줄기 단면은 부등한 삼각형이고 소수 끝이 뾰 족하다 ……………... 송이고랭이 S. triangulata

3. 줄기 단면은 정삼각형이고 소수 끝이 둔하다.

4. 줄기의 가장자리가 날개모양으로 확장되지 않고, 화피편이 수과보다 길거나 같고, 수과 표면에 가로주름이 약하게 있다

.... 좀송이고랭이 S. mucronata var. mucronata

4. 줄기의 가장자리가 날개모양으로 확장되고, 화피편이 수과보다 짧거나 같고, 수과 표면 에 가로주름이 뚜렷하다

.. 나래송이고랭이 S. mucronata var. tatarana

2. 식물체는 중소형이고 줄기 단면은 여러 모양이 섞 여 나거나 원형, 다각형이다.

5. 화서 소수는 대부분 1 개(드물게 2-3개)이고 줄 기의 단면이 원형과 삼각형이 섞여난다

고창고랭이 $S . \times$ uzenensis

5. 화서 소수는 $2-10$ 개이고 줄기의 단면이 원형이 거나 다각형이다.

6. 화피편은 수과와 비슷한 길이 이다.

7. 줄기의 단면은 원형이고, 주두는 3 개로 동일하게 갈라진다 .. 좀올챙이골 S. hotarui

7. 줄기의 단면은 원형-다각형이고, 주두는 2 개(3개일 경우일정하지 않게)로 갈라진다 ...

올챙이골 S. juncoides

6. 화피편은 수과보다 뚜렷이 길다.

8. 줄기 단면은 다각형이다

나도송이고랭이 S. ×trapezoidea

8. 줄기 단면은 원형이다.

9. 인편의 길이는 $2-3 \mathrm{~mm}$ 이다

광릉골 S. komarovii

9. 인편의 길이는 $3.5-4.5 \mathrm{~mm}$ 이다

수원고랭이 S. wallichii

\section{사 사}

본 논문은 정부(환경부)의 재원으로 국립생물자원관의 지원을 받아 수행하였습니다(NIBR NO. 2015-16-101). 올 챙이골속에 관한 여러 가지 정보를 주신 우리식물연구소 의 조양훈 소장님께 진심으로 감사드립니다.

\section{Literature Cited}

Cho, Y. H., J. H. Kim and S. H. Park. 2016. Grasses and Sedges in South Korea. Seoul. (in Korean)

Govaerts, R., J. Koopman, D. Simpson, P. Goetghebeur, K. Wilson, T. Egorova and J. Bruhl. 2012. World checklist of Cyperaceae published update. Trustees of the Royal Botanic Gardens, Kew. Retrieved April 11, 2016, from http:// www.kew.org/wcsp/.

Hayasaka, E. 2000. New Combinations in Japanese Schoenoplectus (Cyperaceae). The Journal of Japanese Botany 75: 223225.

Hayasaka, E. 2012. Delineation of Schoenoplectiella Lye (Cyperaceae), a genus newly segregated from Schoenoplectus (Rchb.) Palla. The Journal of Japanese Botany 87: 169-186.

Im, R. J. 2000. Flora Coreana. The Science and Technology Publishing House, Pyongyang, Korea. (in Korean)

Jung, J. and H. K. Choi. 2010. Systematic rearrangement of Korean Scirpus L. s.l. (Cyperaceae) as inferred from nuclear ITS and chloroplast $r b c L$ sequences. Journal of Plant Biology 53: $222-232$.

Jung, J. and H. K. Choi. 2011. Taxonomic study of Korean Scirpus L. s.l. (Cyperaceae). I. Morphology of Bolboschoenus (Asch.) Palla, Schoenoplectus (Rchb.) Palla, Schoenoplectiella Lye, Scirpus L., and Trichophorum Pers. Korean Journal of Plant Taxonomy 41: 16-34.

Koyama, T. 1958. Taxonomic study of the genus Scirpus Linné. Journal of the Faculty of Science, University of Tokyo, section 3, Botany 7: 271-366.

Lee, T. B. 1999. Illustrated Flora of Korea. Hyangmunsa. Seoul. (in Korean)

Lee, W. T. 1996. Lineamenta Florae Koreae. Academy Press. Seoul. (in Korean)

Lee, Y. N. 2006. New Flora of Korea. Kyohaksa, Seoul. (in Korean)

Lye, K. A. 2003. Schoenoplectiella Lye, gen. nov. (Cyperaceae). Lidia 6: 20-29.

Oh, Y. C. 2007. Cyperaceae. In Genera of Vascular Plants of Korea. Park, C. W. (ed.), Academy Publishing Co., Seoul., Korea. 